OPEN ACCESS

Edited by:

Mohamed Kheireddine Aroua,

Sunway University, Malaysia

Reviewed by:

Luigi Campanella,

Sapienza University of Rome, Italy

Simonetta Antonaroli,

University of Rome tor Vergata, Italy

*Correspondence:

Mickael Capron

mickael.capron@univ-lille.fr

Specialty section

This article was submitted to Green and Sustainable Chemistry,

a section of the journal

Frontiers in Chemistry

Received: 07 December 2018 Accepted: 04 March 2019 Published: 27 March 2019

Citation:

El Roz A, Fongarland P, Dumeignil F and Capron M (2019) Glycerol to

Glyceraldehyde Oxidation Reaction Over Pt-Based Catalysts Under

Base-Free Conditions.

Front. Chem. 7:156.

doi: 10.3389/fchem.2019.00156

\section{Glycerol to Glyceraldehyde Oxidation Reaction Over Pt-Based Catalysts Under Base-Free Conditions}

\author{
Ayman El Roz ${ }^{1}$, Pascal Fongarland ${ }^{2}$, Franck Dumeignil ${ }^{1}$ and Mickael Capron ${ }^{1 *}$ \\ 'CNRS, Centrale Lille, ENSCL, Université d'Artois, UMR 8181-UCCS-Unité de Catalyse et Chimie du Solide, Université de \\ Lille, Lille, France, ${ }^{2}$ Laboratoire de Génie des Procédés Catalytiques, Université Lyon 1, Villeurbanne, France
}

Glycerol valorization through partial oxidation is a good way of obtaining many different molecules with high added value such as glyceric acid, tartronic acid, dihydroxyacetone, etc. Among the potential products, glyceraldehyde is an interesting chemical compound for its various applications in different domains such as organic chemistry, medical, and cosmetic industries. In the present paper, we studied the effect of different supports on the glycerol oxidation reaction in a batch reactor applying base-free conditions. The tested catalysts were Pt-based materials deposited on various supports (i.e., $\mathrm{SiO}_{2}, \mathrm{TiO}_{2}$, ZSM-5, $\gamma-\mathrm{Al}_{2} \mathrm{O}_{3}$ ), which were synthesized using a deposition method followed by a chemical reduction. The catalysts were extensively characterized (BET, ICP, XRD, TEM, XPS), highlighting differences in terms of specific surface areas, textural properties, and Pt nanoparticles sizes. We evidenced a direct relation between glycerol conversion and glyceraldehyde selectivity (i.e., an increase in glycerol conversion leads to a decrease in glyceraldehyde selectivity). The $\mathrm{Pt} / \gamma-\mathrm{Al}_{2} \mathrm{O}_{3}$ catalysts exhibited the highest activity, but their selectivity to glyceraldehyde significantly decreased with time on stream. $\mathrm{Pt} / \mathrm{SiO}_{2}$ presented the highest selectivity to glyceraldehyde owing to a slower reaction rate, which allows envisioning technical opportunities to continuously extract the formed glyceraldehyde from the mixture.

Keywords: glycerol, oxidation, base-free conditions, platinum, glyceraldehyde

\section{INTRODUCTION}

Biomass efficient valorization is an important challenge to ensure the viability of our various industrial sectors (Katryniok et al., 2011; Skrzynska et al., 2015). In fact, the increasing demand for energy, combined with the environmental issues related to climate change, motivates the promotion of the use of renewable energies and biofuels, as well as of the replacement of the fossil raw materials traditionally used in the chemical industry with bioresources (Purushothaman et al., 2014). In this context, biodiesel is obtained by catalytic transesterification of the vegetables oil or animal fat with short chain alcohols, mainly methanol (Ftouni et al., 2015). The main by-product of this reaction is glycerol (accounting for $10 \mathrm{wt} . \%$ based on the initial plant oil quantity). The valorization of this molecule has been intensively studied in several ways, including advanced transformations to value added compounds (Katryniok et al., 2011). Its upgrading by heterogeneous catalysis has been particularly studied, in gas phase to produce for instance acrolein (Katryniok et al., 2009, 2010; Lauriol-Garbey et al., 2011), acrylonitrile (Liebig et al., 2013) or $\mathrm{H}_{2}$ (El Doukkali et al., 2014) but also in liquid phase including conversion to esters or glycerol ethers by 
esterification or etherification, to 1,2-propanediol or 1,3propanediol by hydrogenolysis (Alhanash et al., 2008). The glycerol partial oxidation in the liquid phase can lead to various products such as aldehydes (glyceraldehyde), ketones (dihydroxyacetone), and carboxylic acids (glyceric acid, tartronic acid, glycolic acid, etc.) (Katryniok et al., 2011; Mimura et al., 2014; Skrzynska et al., 2016, 2019; Zaid et al., 2017).

In this paper, we focus on the glycerol oxidation using noble metal catalysts to obtain glyceraldehyde in base free media. Glyceraldehyde is an industrially important chemical compound, which has found applications in the cosmetic industry, organic chemistry and, in pharmaceutical applications. The main difficulty lies in the control of the catalytic selectivity with many possible products through networks of consecutive reactions (Skrzynska et al., 2015; Díaz et al., 2017), which can also ultimately lead to low value products, such as oxalic acid or carbon dioxide. Until now, most of the heterogeneous catalysts used for the oxidation of glycerol are based on noble metals such as platinum, palladium, gold, or even silver (Carrettin et al., 2002, 2003; Zhang et al., 2012; Skrzynska et al., 2014; Ftouni et al., 2015). According to the various studies reported in the literature, it is clear that the gold-based catalysts are active only in basic solution. Under these conditions, glycerol oxidation over supported gold catalysts promotes the production of acids under their salt form, with the necessity of an additional step to recover the desired acids in their native form, yielding a high quantity of waste (i.e., salts resulting from the neutralization). The use of the Ag based catalyst, in basic media, leads to the formation of glycolic acid resulting in an oxidative $\mathrm{C}-\mathrm{C}$ bond cleavage. On the other hand, the platinum based catalysts enable the conversion of glycerol in both acidic and basic solutions and can be selective for the formation of glyceraldehyde in acidic solution or base-free solutions (Carrettin et al., 2002, 2003; Zhang et al., 2012; Skrzynska et al., 2014; Wang et al., 2014; Li and Zaera, 2015). In these previous studies, authors evidence that selectivity is a critical issue. This issue may be solved by tuning the ad hoc noble metal(s)/support couple and adjusting the proper process conditions.

\section{EXPERIMENTAL}

\section{Materials}

Anhydrous glycerol 99\%, from Sigma-Aldrich was used for the catalytic tests, and $\mathrm{H}_{2} \mathrm{SO}_{4}$ from Sigma Aldrich was used for HPLC analysis. Different supports were used for the synthesis of the catalysts: $\mathrm{SiO}_{2}$ MCM-41 from ACS Material and three oxide supports, gamma alumina, titanium oxide, and zeolite ZSM-5, all from Alfa Aesar. Potassium platinum (+IV) chloride and pure sodium hydroxide both from Sigma-Aldrich were used as precursors for the preparation of the Pt-supported catalysts, while sodium borohydride $\left(>96 \% \mathrm{NaBH}_{4}\right.$ ) from Sigma-Aldrich was used as reducing agent and sodium hydroxide $(\mathrm{NaOH} \geq 98 \%)$ from Sigma-Aldrich was used to adjust the $\mathrm{pH}$.

\section{Catalysts Preparation}

The platinum-based materials deposited on various supports (i.e., $\mathrm{SiO}_{2}, \mathrm{TiO}_{2}, \gamma-\mathrm{Al}_{2} \mathrm{O}_{3}, \mathrm{ZSM}-5$ ) were prepared by chemical reduction in the liquid phase. Each powdered oxidic support (about $5 \mathrm{~g}$ ) was suspended in $75 \mathrm{~cm}^{3}$ of ultrapure water and stirred for $60 \mathrm{~min}$ at $67^{\circ} \mathrm{C}$. Then, a solution containing $0.3736 \mathrm{~g}$ $\mathrm{K}_{2} \mathrm{PtCl}_{6} \cdot 6 \mathrm{H}_{2} \mathrm{O}$ (Sigma Aldrich, $\geq 98 \%$ ) dissolved in $25 \mathrm{~cm}^{3}$ of ultrapure water was added dropwise to this suspension to obtain a platinum loading of about $1.5 \mathrm{wt} . \%$ relative to the support in the final material. The temperature of the reaction mixture was maintained at $67^{\circ} \mathrm{C}$ for $60 \mathrm{~min}$ under stirring. Sodium borohydride was used as a reducing agent to reduce the platinum metal. The amount of reducing agent was adjusted with respect to the amount of platinum precursor, each time using a 2-fold stoichiometric excess [11]. The as-obtained gray mixture was further stirred at $67^{\circ} \mathrm{C}$, after adjusting the $\mathrm{pH}$ to 7 with a $0.3 \mathrm{M}$ solution of sodium hydroxide. The suspension was then mixed at $67^{\circ} \mathrm{C}$ for $90 \mathrm{~min}$ and a gray solid was recovered by filtration, washed with $100 \mathrm{~cm}^{3}$ of distilled water and dried at $110^{\circ} \mathrm{C}$ for $24 \mathrm{~h}$ prior testing. A series of catalysts with a nominal content of platinum of $1.5 \mathrm{wt} . \%$ was then obtained.

\section{Catalysts' Characterization}

The textural properties (specific surface area, pore volume and mean pore size) of the catalysts were analyzed by $\mathrm{N}_{2}$ adsorptiondesorption using a Micromeritics Tristar-II 3020 instrument. Prior to the analysis, the samples were outgassed at $110^{\circ} \mathrm{C}$ for $7 \mathrm{~h}$ under vacuum. To determine the Pt loading in the catalysts, inductively coupled plasma-atomic emission spectroscopy (ICPAES, Vista Pro Varian) was used. The samples were prepared by dissolving the catalysts in a $\mathrm{Hot} \mathrm{Block} / \mathrm{HCl} / \mathrm{HNO}_{3}$ digestion. The dispersion of $\mathrm{Pt}$ is determined by $\mathrm{H}_{2}$ chemisorption using Micromeritics Autochem II 2920 instrument. Prior to the analysis, pure $\mathrm{H}_{2}$ (i.e., $30 \mathrm{~mL} / \mathrm{min}$ ) was used to reduce the samples at $500^{\circ} \mathrm{C}$ (i.e., $10^{\circ} \mathrm{C} / \mathrm{min}$ ); Then an $\mathrm{Ar}$ flux (i.e., $50 \mathrm{~mL} / \mathrm{min}$ ) was used for $1 \mathrm{~h}$ at $500^{\circ} \mathrm{C}$ before a return to room temperature and 10 injections $(20 \mu \mathrm{L})$ of $\mathrm{H}_{2}$ in Ar were carried out. The crystalline phases present in the catalysts were analyzed by XRD at ambient temperature on Bruker D8 Advance instrument, equipped with a $\mathrm{CuK} \alpha$ source $(\lambda=0.154 \mathrm{~nm})$. The samples were scanned at a rate of $0.02^{\circ}$ over the $5^{\circ} \leq 2 \theta \leq$ $90^{\circ}$ range with an integration time of $0.5 \mathrm{~s}$. The diffractograms were indexed using the JCPDS database. The oxidation state of platinum and its quantification on the surface of catalysts were determined by XPS analysis (AXIS Ultra Kratos) using a monochromatized aluminum source $(\mathrm{AlK} \alpha=1486.6 \mathrm{eV}, 150 \mathrm{~W})$, and the value of the $\mathrm{C} 1 \mathrm{~s}$ core level $(285 \mathrm{eV})$ was used for the calibration of the energy scale. Curve fitting was performed using the Casa XPS software applying a Shirley-type background subtraction. To determine the size of the platinum particles, transmission electron microscopy analysis was used. TEM FEI Tecnai G2-20 twin, working with an accelerating potential of $200 \mathrm{kV}$ and equipped with a slow-scan CCD camera, enabled the observation of samples with a very high resolution $(2-5 \mathrm{~nm}$ scale). The samples for TEM were prepared from a diluted suspension of catalyst in ethanol. A drop of suspension was placed on a Lacey carbon-coated grid and allowed to dry in air. The particle size distribution was calculated by counting over 200 particles over multiple areas using the ImageJ software. 


\section{Catalytic Performance Evaluation}

The glycerol oxidation reaction in the liquid phase was carried out in a $300 \mathrm{~cm}^{3}$ semi-batch stainless steel reactor (PARR 5500 HP Series Compact Reactors), equipped with a thermocouple and a thermo-regulated oxygen supply system. For each experiment, $200 \mathrm{~cm}^{3}$ of an $0.1 \mathrm{M}$ glycerol aqueous solution were heated to $80^{\circ} \mathrm{C}$. The reaction was started at the temperature of $80^{\circ} \mathrm{C}$ when $0.5 \mathrm{~g}$ of the selected catalyst was introduced into the reactor immediately pressurized with 2 bar oxygen $\left(t_{0}\right)$. The products were periodically sampled and analyzed with an Agilent 1260 HPLC, equipped with an Aminex HPX-87H column $(300 \times 7.8 \mathrm{~mm})$ and a reflective index detector (RID). A solution of $\mathrm{H}_{2} \mathrm{SO}_{4}(0.0025 \mathrm{M})$ in deionized water (flow rate: $0.5 \mathrm{~cm}^{3} \cdot \mathrm{min}^{-1}$ ) was used as an eluent. The identification and

TABLE 1 | List of the prepared catalysts with the corresponding acronyms, specific surface area (SSABET), the BJH desorption branch-deduced average pore diameter ( $\mathrm{d}_{\text {pores }}$ ) and the BJH desorption branch-derived cumulative pore volume $\left(V_{\text {pores }}\right)$.

\begin{tabular}{lcc}
\hline Catalyst & $\begin{array}{c}\text { Pt loading } \\
\text { (ICP)/Me wt.\% }\end{array}$ & $\begin{array}{c}\text { Pt dispersion } \\
\left(\mathbf{H}_{\mathbf{2}} \text { chemisorption)/\% }\right.\end{array}$ \\
\hline $\mathrm{Pt} / \mathrm{SiO}_{2}$ & 1.20 & 1 \\
$\mathrm{Pt} / \mathrm{ZSM} 5$ & 1.36 & 1.5 \\
$\mathrm{Pt} / \mathrm{TiO} \mathrm{O}_{2}$ & 1.15 & 24.5 \\
$\mathrm{Pt} / \gamma-\mathrm{Al}_{2} \mathrm{O}_{3}$ & 1.29 & 32.7
\end{tabular}

quantification of the reaction products were performed using the corresponding calibration curves plotted upfront.

\section{RESULTS AND DISCUSSION \\ Catalysts Characterization \\ BET}

The results of the textural analysis of the catalysts are presented in Table 1. Compared to supports alone, no change can be noted in terms of specific surface area for $\mathrm{Pt} / \mathrm{SiO}_{2}, \mathrm{Pt} / \mathrm{TiO}_{2}, \mathrm{Pt} / \mathrm{ZSM}-5$, and $\mathrm{Pt} / \gamma-\mathrm{Al}_{2} \mathrm{O}_{3}$. The silica-supported catalyst $\left(\mathrm{SiO}_{2}-\mathrm{MCM} 41\right)$ exhibits the largest specific surface area (i.e., $625 \mathrm{~m}^{2} / \mathrm{g}$ ) and the largest pore volume $\left(0.575 \mathrm{~cm}^{3} / \mathrm{g}\right)$, but an average pore diameter of $2.7 \mathrm{~nm}$. Pt/ZSM-5 and $\mathrm{Pt} / \mathrm{TiO}_{2}$ have lower specific surface areas of 358 and $167 \mathrm{~m}^{2} / \mathrm{g}$, respectively (Table 2). It can be noted that $\mathrm{Pt} / \gamma-\mathrm{Al}_{2} \mathrm{O}_{3}$ has the lowest specific surface area $\left(57 \mathrm{~m}^{2} / \mathrm{g}\right)$, but a higher pore diameter than the other studied materials $(25.7 \mathrm{~nm})$.

\section{XRD}

The diffractograms of catalysts are presented in Figure 1. The diffractogram of the $\mathrm{TiO}_{2}$ support (Figure 1A) shows well resolved diffraction peaks, characteristic of the crystallized anatase phase in a tetragonal face-centered system (PDF 00021-1272). There is no significant change in the diffractogram after platinum addition is observed. Figure 1B shows the diffractogram of the catalyst supported on gamma-alumina (PDF 001-1303). The diffractograms of the catalyst support
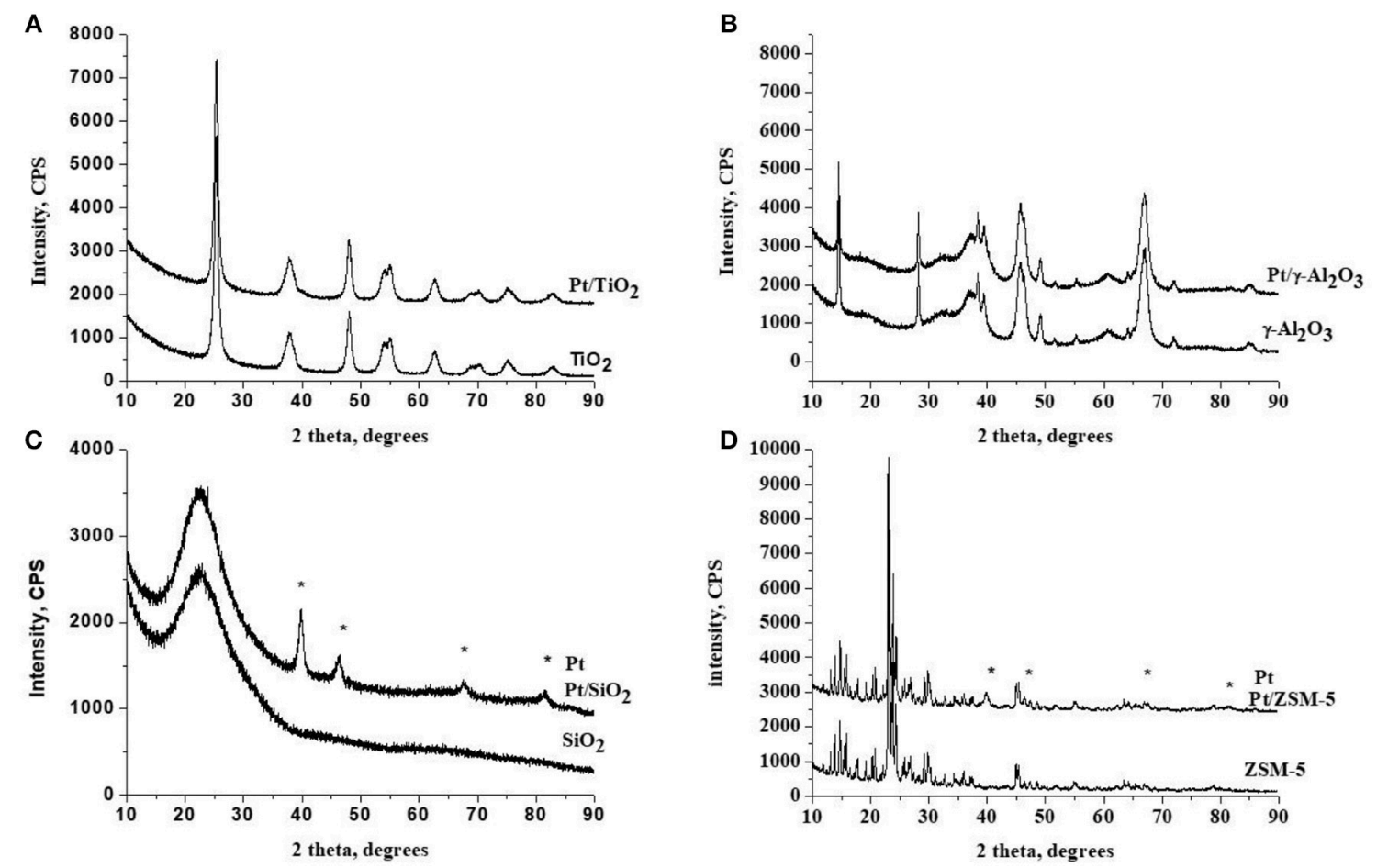

FIGURE 1 | X-ray diffractograms of the fresh catalysts and of the corresponding supports with the position of the main diffraction lines expected for the metallic particles. Symbols (*) corresponds to: Pt. (A) $\mathrm{TiO}_{2}$ as support, (B) $\gamma-\mathrm{Al}_{2} \mathrm{O}_{3}$ as support, (C) $\mathrm{SiO}_{2}$ as support and (D) ZSM-5 as support. 

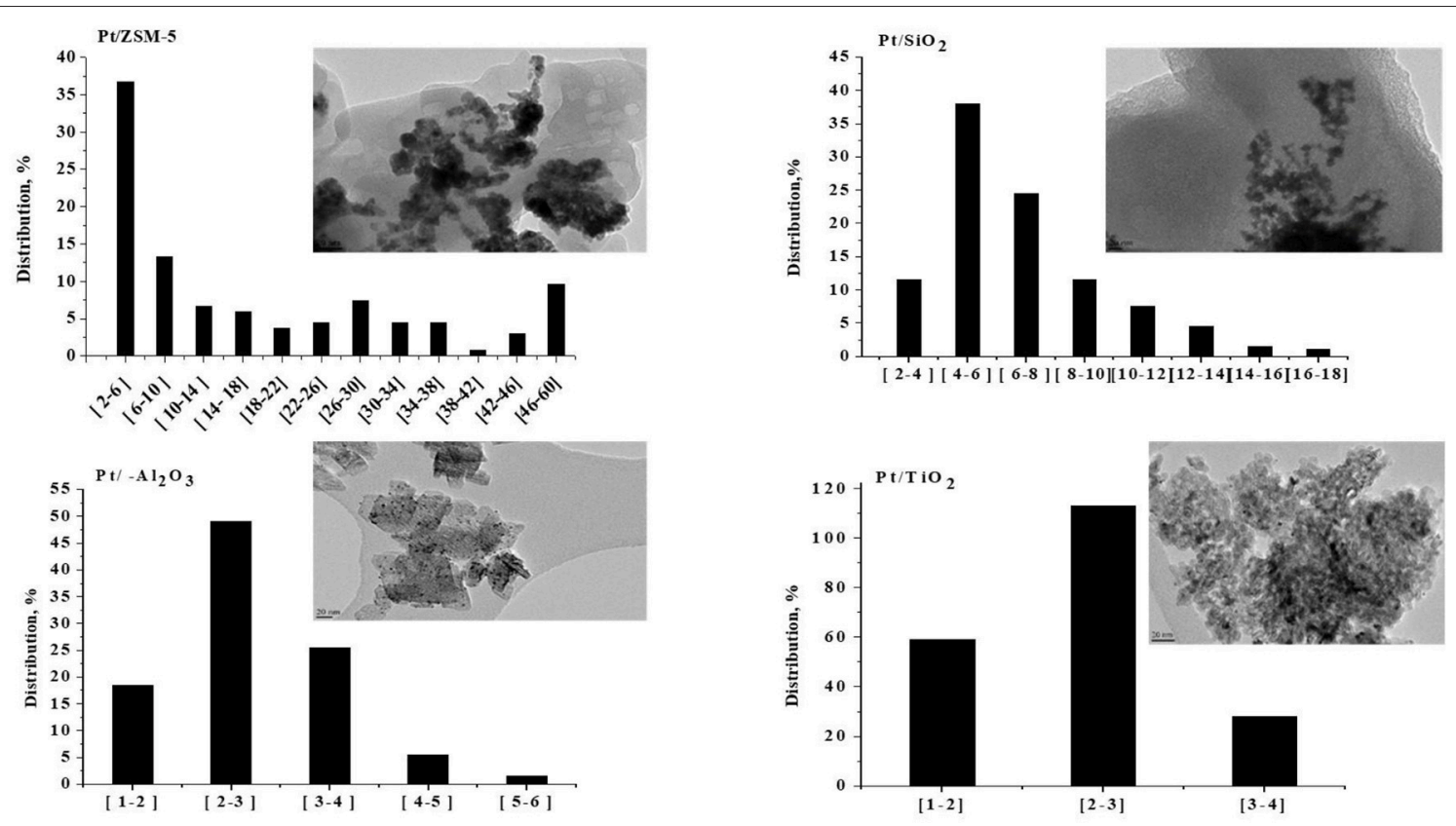

FIGURE 2 | TEM images and histograms of the metallic particle size distributions observed over the prepared catalysts.

are identical. The diffractogram of the $\mathrm{SiO}_{2} \mathrm{MCM}-41$ support (Figure 1C) has a very large and low intensity line representative of the amorphous character of this support. The appearance of several additional peaks on the $\mathrm{Pt} / \mathrm{SiO}_{2}$ diffractogram is attributed to the presence of crystallized metallic platinum in a face-centered cubic lattice (JCPDS No. 04-0802). The diffractogram of the ZSM-5 support (Figure 1D) has well resolved diffraction peaks, characteristic of ZSM-5 zeolite. The appearance of additional peaks after Pt deposition (which are similar to those observed for silica MCM-41) is also attributed to the presence of crystallized metallic platinum (JCPDS No. 040802). According to the diffractogram analysis of the various catalysts, it can be concluded that the platinum supported on $\mathrm{TiO}_{2}$ and $\gamma-\mathrm{Al}_{2} \mathrm{O}_{3}$ is predominantly present under the form of small particles (with XRD, particles with a size $<5 \mathrm{~nm}$ can be hardly identified). The clear appearance of characteristic diffraction peaks assigned to metallic platinum over $\mathrm{SiO}_{2}$ and ZSM-5 suggests the presence of Pt particles larger than $5 \mathrm{~nm}$, which will be confirmed by TEM analysis (vide supra).

\section{ICP \& $\mathrm{H}_{2}$ Chemisorption}

The results of the elemental analysis of the catalysts prepared shown in Table 1 confirm that the actual amount of deposited platinum is close to the theoretical one (i.e., 1.5 wt.\%). Metal dispersions obtained by chemisorption of $\mathrm{H}_{2}$ are summarized in Table 1 as well. A very low platinum dispersion is obtained for $\mathrm{Pt} / \mathrm{SiO}_{2}$ and Pt/ZSM-5 ( 1 and $1.5 \%$, respectively). On the other hand, the platinum dispersion on $\mathrm{TiO}_{2}$ and $\gamma-\mathrm{Al}_{2} \mathrm{O}_{3}$ is much better, with respective values of 24.5 and $32.7 \%$. These results suggest an agglomeration of the platinum particles on the two silicic supports. This is in agreement with the XRD analyzes results (i.e., detection of a metallic Pt phase suggesting particle sizes larger than $5 \mathrm{~nm}$ ).

\section{TEM}

Figure 2 presents the TEM images of supported platinumbased catalysts, as well as the particle size distribution. A non-homogeneous distribution and aggregations of platinum particles were observed for $\mathrm{Pt} / \mathrm{SiO}_{2}$. Over this sample, more than $50 \%$ of the particles have a size $<6 \mathrm{~nm}$, but the distribution extends to sizes larger than $18 \mathrm{~nm}$. Note that we did not analyze all the agglomerated particles on the TEM pictures for that sample, which means that the actual number of very large agglomerates/particles is even underestimated. The TEM images of Pt/ZSM-5 catalyst show that the platinum particles' size distribution is not homogeneous over this sample with the presence of aggregates of platinum particles. One third of the population has a size between 2 and $6 \mathrm{~nm}$, more than half is within the range of $6-36 \mathrm{~nm}$ and the remainder has a diameter larger than $36 \mathrm{~nm}$. This agrees with the XRD observations as well. Concerning the $\mathrm{Pt} / \mathrm{TiO}_{2}$ catalyst, the particle size distribution is centered on $2-3 \mathrm{~nm}$ with $55 \%$ of the particles in this range. The largest size observed is $4 \mathrm{~nm}$. This result agrees with the observed metal dispersion $(24.44 \%)$ and the absence of Pd peaks on the $\mathrm{XRD}$ diffractograms. Finally, The $\mathrm{Pt} / \gamma-\mathrm{Al}_{2} \mathrm{O}$ catalyst has the best dispersion among all of the studied samples, with a particle size distribution centered on $2-3 \mathrm{~nm}$, it gathered $50 \%$ of the total population. The largest size observed is $6 \mathrm{~nm}$.

\section{XPS}

The chemical surface composition of the samples has been studied by XPS. This study is based, for platinum, on the analysis of the Pt $4 \mathrm{f}$ levels for $\mathrm{Pt} / \mathrm{SiO}_{2}, \mathrm{Pt} / \mathrm{TiO}_{2}$, and $\mathrm{Pt} / \mathrm{ZSM}-5$ and of 

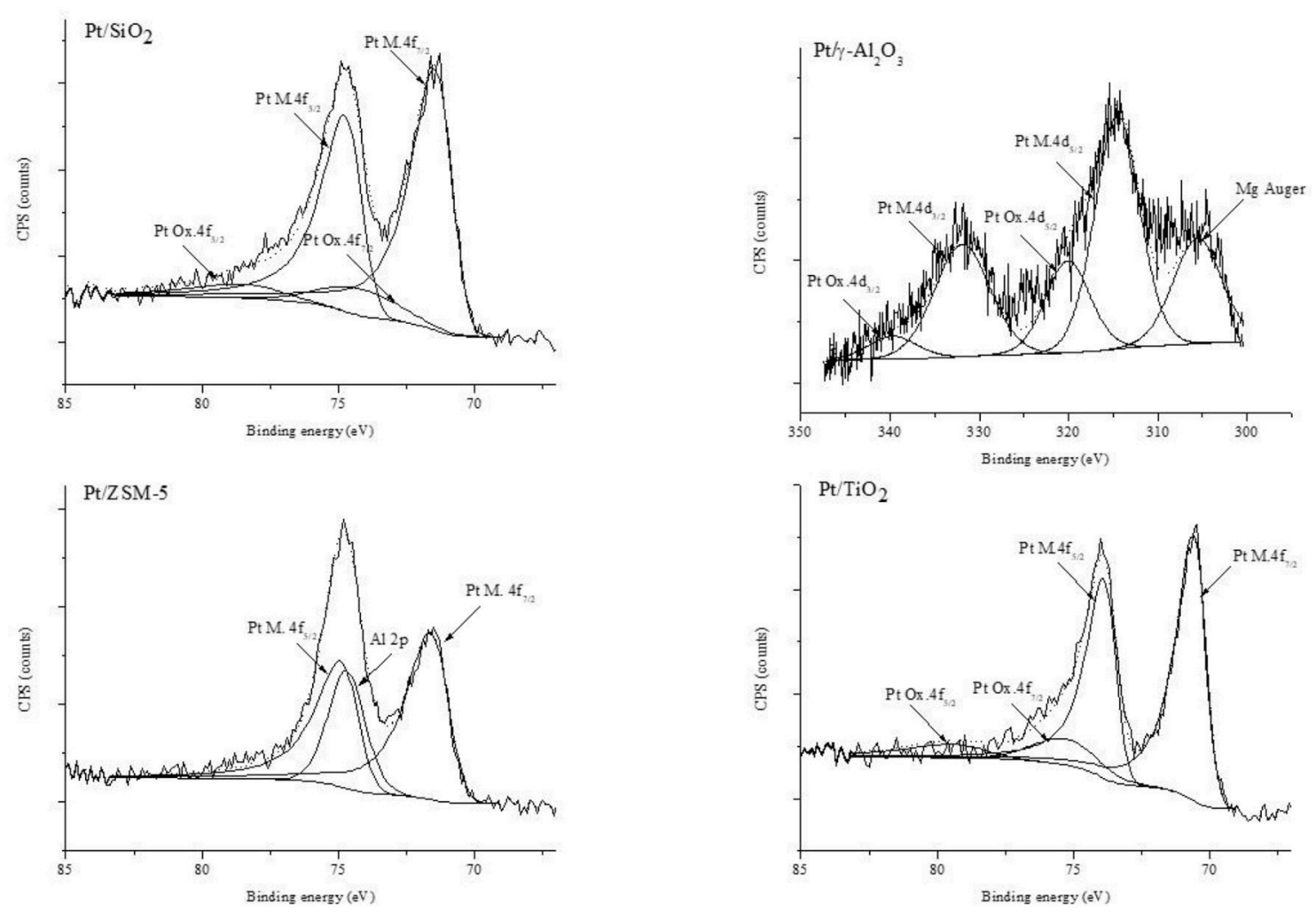

FIGURE 3 | XPS spectra of the Pt 4d or Pt $4 \mathrm{f}$ levels with the corresponding BE values observed over the prepared catalysts.

the Pt $4 \mathrm{~d}$ level for $\mathrm{Pt} / \gamma-\mathrm{Al}_{2} \mathrm{O}_{3}$. Indeed, for this latter, the Pt $4 \mathrm{f}$ photopeak overlaps that of $\mathrm{Al} 2 \mathrm{p}$, which makes it unexploitable. It should be noted that the percentage of aluminum in the ZSM-5 support is lower than in the $\gamma-\mathrm{Al}_{2} \mathrm{O}_{3}$, and that it is therefore possible to separate the $\mathrm{Pt} 4 \mathrm{f}$ and $\mathrm{Al} 2 \mathrm{p}$ photopeaks for this sample. Figure 3 shows the corresponding spectra obtained for all the catalysts. The spectrum of $\mathrm{Pt} / \mathrm{TiO}_{2}$ shows two photoelectron peaks at binding energies of $70.28 \mathrm{eV}\left(\mathrm{Pt}_{4 / 2}\right)$ and $73.58 \mathrm{eV}\left(\mathrm{Pt} 4 \mathrm{f}_{5 / 2}\right)$. These binding energies correspond to those expected for $\mathrm{Pt}^{\mathrm{O}}$ (Hu et al., 2010). The other two photoelectron peaks are located at binding energies of $75.30 \mathrm{eV}\left(\mathrm{Pt}_{4 / 2}\right)$ and $78.60 \mathrm{eV}\left(\mathrm{Pt} 4 \mathrm{f}_{5 / 2}\right)$ and are characteristic of platinum in the oxidic form (Skrzynska et al., 2015; "X-ray Photoelectron Spectroscopy (XPS) Reference Pages, Element: Platinum, Home page: http://www.xpsfitting.com (access 15thSep. 2018)., n.d.). We determined that platinum oxide represents about $15 \%$ of the total platinum Table 3. Concerning the Pt/ZSM-5 catalyst, two photoelectrons peaks characteristic of platinum metal, located at binding energies of $71.65 \mathrm{eV}\left(\mathrm{Pt} 4 \mathrm{f}_{7 / 2}\right)$ and $74.95 \mathrm{eV}\left(\mathrm{Pt}_{4 / 2}\right)$, and a photoelectron peak corresponding to $\mathrm{Al} 2 \mathrm{p}$ level, located at a binding energy of $74.66 \mathrm{eV}$, could be observed. The platinum analyzed in this catalyst was therefore $100 \%$ in the metallic form $\left(\mathrm{Pt}^{\mathrm{O}}\right)$. As for $\mathrm{Pt} / \mathrm{SiO}_{2}$, the spectrum obtained is composed of two photoelectron peaks characteristic of $\mathrm{Pt}^{\mathrm{O}}$ at binding energies of $71.0 \mathrm{eV}\left(\mathrm{Pt} 4 \mathrm{f}_{7 / 2}\right)$ and $74.33 \mathrm{eV}\left(\mathrm{Pt}_{4} \mathrm{f}_{5 / 2}\right)$ and two photoelectron peaks characteristic of platinum in the oxidic form,
TABLE 2 | List of catalysts prepared with the acronyms, the actual platinum metal loading estimated by elemental analysis (ICP), and dispersion estimated by $\mathrm{H}_{2}$-Chemisorption.

\begin{tabular}{|c|c|c|c|c|}
\hline \multirow{2}{*}{$\begin{array}{l}\text { Catalyst } \\
\text { name }\end{array}$} & \multirow{2}{*}{\multicolumn{2}{|c|}{$\begin{array}{c}\text { Support } \\
S S A_{B E T}\left(\mathrm{~N}_{2}-\mathrm{BET}\right) / \mathrm{m}^{2} \cdot \mathrm{g}^{-1}\end{array}$}} & \multicolumn{2}{|c|}{ Catalyst } \\
\hline & & & $V_{\text {poresBJH }}$ & $d_{\text {pores }}(\mathrm{nm})$ \\
\hline $\mathrm{Pt} / \mathrm{SiO}_{2}$ & 635 & 625 & 0.575 & 2.7 \\
\hline $\mathrm{Pt} / \mathrm{ZSM}-5$ & 361 & 358 & 0.165 & 8.2 \\
\hline $\mathrm{Pt} / \mathrm{TiO}_{2}$ & 173 & 167 & 0.396 & 6.5 \\
\hline $\mathrm{Pt} / \gamma-\mathrm{Al}_{2} \mathrm{O}_{3}$ & 57 & 56 & 0.394 & 25.7 \\
\hline
\end{tabular}

located at binding energies of $74.23 \mathrm{eV}\left(\mathrm{Pt} 4 \mathrm{f}_{7 / 2}\right)$ and $77.53 \mathrm{eV}$ ( $\mathrm{Pt} 4 \mathrm{f}_{5 / 2}$ ). Regarding the $\mathrm{Pt} / \gamma-\mathrm{Al}_{2} \mathrm{O}_{3}$ sample, two components characteristic of $\mathrm{Pt}$ in the metallic form ( $\mathrm{Pt} 4 \mathrm{~d}_{5 / 2}$ and $\mathrm{Pt} 4 \mathrm{~d}_{3 / 2}$ localized at binding energies 314.55 and $331.93 \mathrm{eV}$, respectively) and two peaks characteristic of platinum in the oxidic form (at 320.08 and $339.72 \mathrm{eV}$, respectively), were observed. Furthermore, the presence of a photoelectron peak located at a binding energy of $305.04 \mathrm{eV}$ was noted, corresponding to an impurity that could be magnesium (Mg Auger) present as impurity in one of the precursors used during the synthesis.

The results of the XPS analyses as well as the quantification of the different species are summarized in Table 3, below. 
The $\mathrm{Pt} / \mathrm{M}$ atomic ratios are larger for the $\mathrm{Pt} / \mathrm{TiO}_{2}$ and $\mathrm{Pt} / \gamma$ $\mathrm{Al}_{2} \mathrm{O}_{3}$, which can be explained by the better dispersion of Pt over these catalysts.

\section{Catalytic Performances \\ Evolution of Selectivity as a Function of Time}

The evolution of the quantity of the different products formed during a catalytic oxidation reaction of glycerol in liquid phase, using a $\mathrm{Pt} / \mathrm{SiO} 2$ sample as an example under $0.1 \mathrm{M}$ glycerol solution with 2 bars of oxygen at $80^{\circ} \mathrm{C}$, was studied. As well as that, the consumption of glycerol as a function of time are shown

TABLE 3 | Binding energies of the Pt $4 \mathrm{f} 7 / 2$ level for the $\mathrm{Pt}$ on $\mathrm{SiO}_{2}, \mathrm{TiO}_{2}, \mathrm{ZSM}-5$ catalysts, and of the $\mathrm{Pt} 4 \mathrm{~d} 5 / 2$ level for $\mathrm{Pt} / \gamma-\mathrm{Al}_{2} \mathrm{O}_{3}$; Surface Pt/M atomic ratios with $\mathrm{M}=\mathrm{Si}(2 \mathrm{p})$, Ti (2p) ou Al (2p).

\begin{tabular}{lccccc}
\hline Catalyst & $\begin{array}{c}\mathbf{P t} \mathbf{4 f}_{\mathbf{7} / \mathbf{2}} \\
\text { metallic } \\
\mathbf{( e V )}\end{array}$ & $\begin{array}{c}\mathbf{P t} \mathbf{4 f}_{\mathbf{7} / \mathbf{2}} \\
\text { oxide } \\
\mathbf{( e V )}\end{array}$ & $\begin{array}{c}\text { Mol\% Pt } \\
\text { metallic }\end{array}$ & $\begin{array}{c}\text { Mol\% } \mathbf{P t} \\
\text { oxide }\end{array}$ & $\begin{array}{c}\mathbf{P t} / \mathbf{M} \\
\text { (atom/atom) }\end{array}$ \\
\hline $\mathrm{Pt} / \mathrm{SiO}_{2}$ & 71.0 & 74.2 & 87 & 13 & 0.008 \\
$\mathrm{Pt} / \mathrm{TiO}_{2}$ & 70.3 & 75.3 & 85 & 15 & 0.022 \\
$\mathrm{Pt} / \mathrm{ZSM}-5$ & 71.2 & - & 100 & - & 0.005 \\
$\mathrm{Pt} / \gamma-$ & $\mathbf{4 d} 5 / 2$ & $\mathbf{4} \mathbf{d}_{5 / 2}$ & 76 & 24 & 0.014 \\
$\mathrm{Al}_{2} \mathrm{O}_{3}$ & 314.5 & 320.0 & & & \\
\hline
\end{tabular}

The bold text signifies that the XPS contribution was changed for this sample due to the fact that there was a significant overlap in 4f7/2 with the Al contribution. in Figure 4 (right). Also, Figure 4 (left) presents the same data in the form of glycerol conversion and selectivities to products. At the beginning of the reaction, the oxidation of the primary hydroxyl group first leads to the formation of glyceraldehyde with a very rapid increase in the number of moles in the first 5 min with 13 mmol.mol ${ }^{-1}$ Pt.h ${ }^{-1}$ as the initial formation rate. After $5 \mathrm{~min}$, the rate of glyceraldehyde formation decreases. Further, the number of moles of glyceraldehyde remains stable after $300 \mathrm{~min}$. On the other hand, glyceric acid appears after $8 \mathrm{~min}$ of reaction and its quantity progresses linearly. Two other minor products (i.e., glycolic acid and glyoxal) appear at the beginning of the reaction, without any subsequent evolution of their quantity with time. In terms of selectivity, Figure 4 shows that the glyceraldehyde selectivity reaches $90 \%$ after $8 \mathrm{~min}$ and then progressively decreases to $58 \%$ after $340 \mathrm{~min}$. The selectivity to glyceric acid increases gradually to $38 \%$ after $340 \mathrm{~min}$.

Owing to the obtained results, a reaction scheme (Figure 5) was proposed to explain the formation of the products (Katryniok et al., 2011). The first step of the reaction is the oxidation of the primary hydroxyl to form glyceraldehyde (primary product). The latter can be oxidized to glyceric acid or undergo oxidative $\mathrm{C}-\mathrm{C}$ cleavage to form glycolic acid and carbon dioxide, as secondary products.

\section{Influence of the Support}

The catalytic tests of the glycerol oxidation in the liquid phase were carried out for the four catalysts and the results are
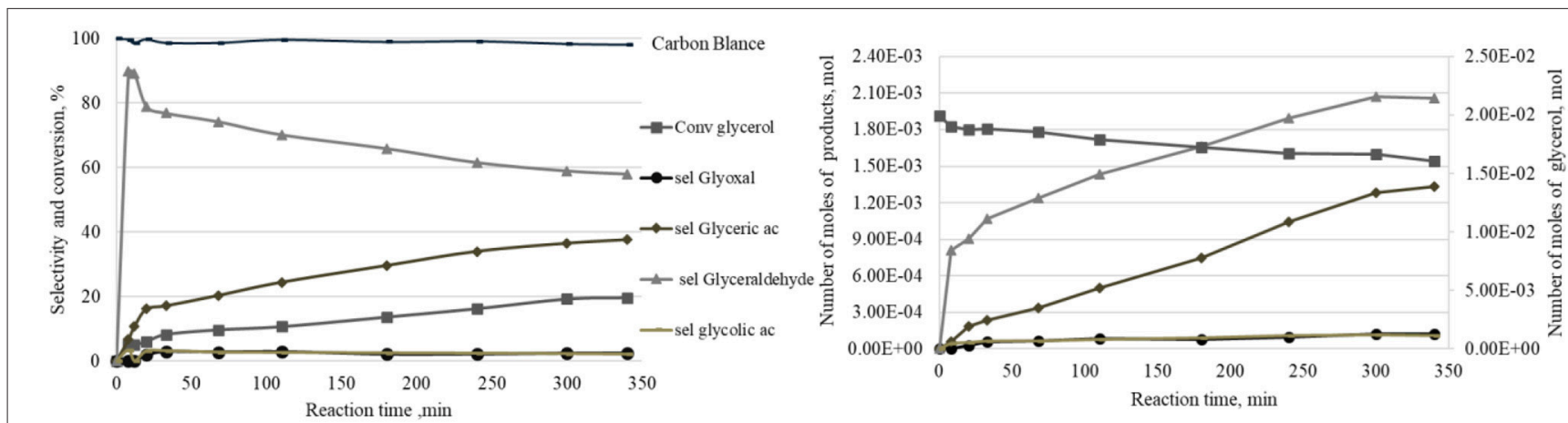

FIGURE 4 | Evolution of the products quantities as a function of time under the following reaction conditions: $0.5 \mathrm{~g}$ of Pt/SiO $2,200 \mathrm{~cm}^{3}$ of an aqueous $0.1 \mathrm{M} \mathrm{GLY}$ solution, 2 bars of oxygen, $1,000 \mathrm{rpm}$, temperature $80^{\circ} \mathrm{C}$.<smiles>CC(C)(C)C(=O)CO</smiles>

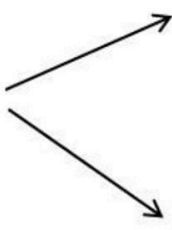<smiles>O=C(O)C(O)CO</smiles>

Glyceric acid<smiles>O=C(O)C[OH+]</smiles>

Glycolic acid

FIGURE $\mathbf{5}$ | The proposed scheme of the oxidation of glycerol in base-free solution. 


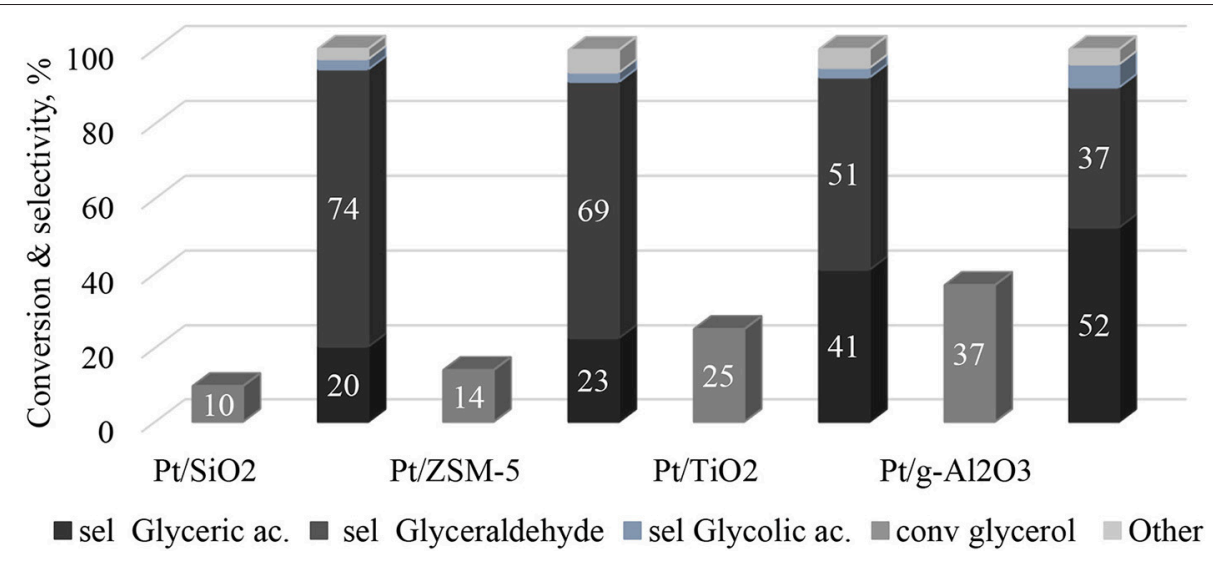

FIGURE 6 | Conversion and selectivity of products during glycerol partial oxidation over the prepared catalysts. Reaction conditions: $0.5 \mathrm{~g}$ of catalysts, $200 \mathrm{~cm}^{3}$ of an aqueous $0.1 \mathrm{M} \mathrm{GLY}$ solution, 2 bars of oxygen, 1,000 rpm, temperature $80^{\circ} \mathrm{C}, 1 \mathrm{~h}$.

presented in Figure 6. The best performance is obtained with $\mathrm{Pt} / \gamma-\mathrm{Al}_{2} \mathrm{O}_{3}$ with a glycerol conversion of $37 \%$ after $60 \mathrm{~min}$ of the reaction (with an initial glycerol conversion speed of $48 \mathrm{mmol}$ glycerol. $\mathrm{mol}^{-1} \mathrm{Pt} \cdot \mathrm{h}^{-1}$ ). After the same reaction time, the $\mathrm{Pt} / \mathrm{TiO}_{2}$ catalyst converts $25 \%$ of glycerol with an initial glycerol conversion rate of $52 \mathrm{mmol}$ glycerol. $\mathrm{mol}^{-1} \mathrm{Pt}^{-\mathrm{h}^{-1}}$. Finally, the $\mathrm{Pt} / \mathrm{SiO}_{2}$ and $\mathrm{Pt} / \mathrm{ZSM}-5$ catalysts are much less active with glycerol conversions of 10 and $14 \%$, respectively, after $1 \mathrm{~h}$ (and initial glycerol conversion rates of 16 and $14 \mathrm{mmol}$ glycerol. $\mathrm{mol}^{-1} \mathrm{Pt} . \mathrm{h}^{-1}$, respectively). These differences can be interpreted according to the aforementioned characterization results. The analysis of the platinum dispersion showed that the platinum on $\mathrm{SiO}_{2}$ and on ZSM-5 is weakly dispersed, but well dispersed on $\mathrm{TiO}_{2}$ and $\gamma-\mathrm{Al}_{2} \mathrm{O}_{3}$. This result was confirmed by TEM analysis, which showed an agglomeration of platinum over $\mathrm{SiO}_{2}$ and ZSM-5. Therefore, this suggests that the number of active sites accessible on the $\mathrm{Pt} / \mathrm{SiO}_{2}$ and $\mathrm{Pt} / \mathrm{ZSM}-5$ catalysts is lower than on the $\mathrm{Pt} / \mathrm{TiO}_{2}$ and $\mathrm{Pt} / \gamma-\mathrm{Al}_{2} \mathrm{O}_{3}$ catalysts. This result was further corroborated by XPS analysis, which showed that the atomic ratios (i.e., $\mathrm{Pt} / \mathrm{M}$, Atom/Atom) are lower for the $\mathrm{Pt} / \mathrm{SiO}_{2}$ and Pt/ZSM-5 catalysts (Table 3 )

Figure 7 shows the relationship between the initial rate of glycerol conversion and the average particle size of Pt. It is evident that from $\sim 6 \mathrm{~nm}$, the initial rate of transformation seems constant. According to Figure 6, the selectivity to glyceraldehyde (74\%) is higher for the less active catalyst $\left(\mathrm{Pt} / \mathrm{SiO}_{2}-10 \%\right.$ glycerol conversion and $20 \%$ glycerol acid selectivity after $60 \mathrm{~min}$ of reaction). The $\mathrm{Pt} / \gamma-\mathrm{Al}_{2} \mathrm{O}_{3}$ catalyst is the most active in the series studied with a $37 \%$ glycerol conversion after $60 \mathrm{~min}$ of the reaction, predominantly producing glyceric acid $(52 \%)$. It clearly exists a dependence between glyceraldehyde and glycerol acid selectivity and glycerol conversion, which is common for successive reactions of the $A \rightarrow B \rightarrow C$ type. To interpret these results, the evolution of glyceraldehyde selectivity was plotted as a function of conversion for all of the catalysts. Figure 8 shows that the selectivity of the glyceraldehyde linearly decreases with the increase in conversion, and therefore the most active catalyst will have a low glyceraldehyde selectivity, which is the case for the $\mathrm{Pt} / \mathrm{Al}_{2} \mathrm{O}_{3}, \mathrm{Pt} / \mathrm{TiO}_{2}$, and Pt/ZSM-5.

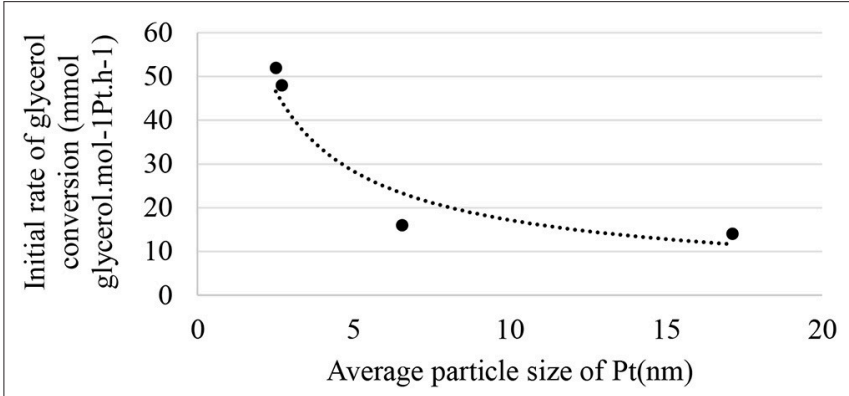

FIGURE 7 | Relationship between the initial rate of glycerol conversion and the average particle size of Pt.

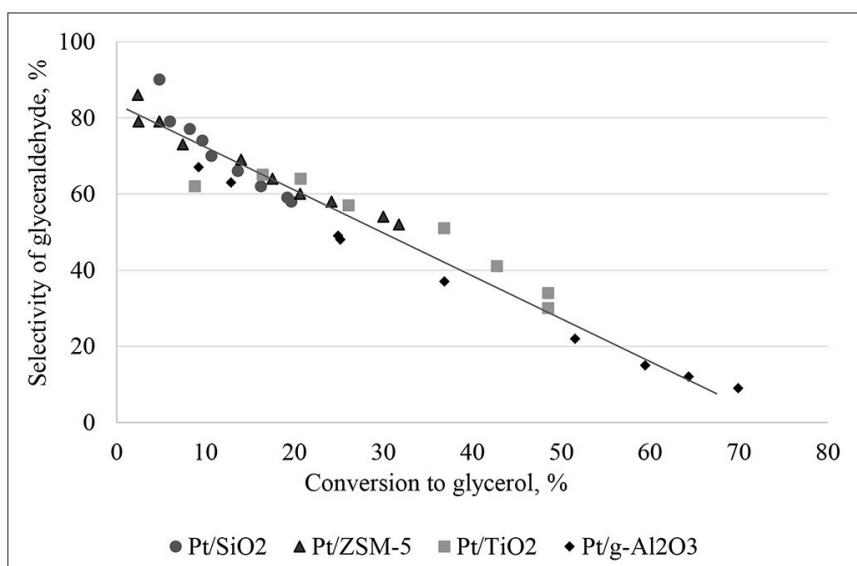

FIGURE 8 | Relationship between the selectivity of glyceraldehyde and the conversion to glycerol.

\section{CONCLUSION}

In this work, we synthesized four Pt based catalysts changing the support. XPS characterizations evidence that the platinum was mainly reduced but not totally for most used supports with a reduction level higher than $80 \%$. The nature of the 
catalytic support clearly influences the platinum particle size and the dispersion of the particles has been demonstrated. The silicic supports studied generate aggregation of the platinum particles leading to a high average particle size (i.e., $6.5 \mathrm{~nm}$ ) Contrary to that, using $\mathrm{TiO}_{2}$ or $\gamma-\mathrm{Al}_{2} \mathrm{O}_{3}$ as supports leads to very small particles (i.e., $2.7 \mathrm{~nm}$ ) with a narrow size distribution. The average particle size leads to a significant change in the initial rates of glycerol oxidation in the liquid phase in a base-free solution. The catalyst having a low dispersion has a particle size distribution spread over a wide range and a larger average particle size (i.e., fewer active sites), inducing a lower glycerol conversion and initial transformation rate on these materials. We have also demonstrated a real dependence between target molecule selectivity (i.e., glyceraldehyde) and substrate conversion, where the selectivity of glyceraldehyde decreases with increasing glycerol conversion. At the same time, the oxidation of glyceraldehyde leads to the formation of glyceric acid, which does not seem to be transformed anymore in our reaction conditions. Thanks to our work, we have designed a series of catalysts able to transform glycerol either in glyceraldehyde or in glyceric acid in base free media, depending on material choice. In order to achieve high glyceraldehyde selectivity, low glycerol conversion is needed followed by a separation process. In this case, the $\mathrm{Pt} / \mathrm{SiO}_{2}$ is a good candidate due to the fact that its initial transformation rate is lower allowing an easier separation process. If the goal is to obtain glyceric acid with high selectivity, $\mathrm{Pt} / \gamma-\mathrm{Al}_{2} \mathrm{O}_{3}$ is much more suitable.

\section{REFERENCES}

Alhanash, A., Kozhevnikova, E. F., and Kozhevnikov, I. V. (2008). Hydrogenolysis of glycerol to propanediol over Ru: polyoxometalate bifunctional catalyst. Catal. Lett. 120, 307-311. doi: 10.1007/s10562-007-9286-3

Carrettin, S., McMorn, P., Johnston, P., Griffin, K., and Hutchings, G. J. (2002). Selective oxidation of glycerol to glyceric acid using a gold catalyst in aqueous sodium hydroxide. Chem. Commun. 7, 696-697. doi: 10.1039/b201112n

Carrettin, S., McMorn, P., Johnston, P., Griffin, K., Kiely, C. J., and Hutchings, G. J. (2003). Oxidation of glycerol using supported Pt, Pd and Au catalysts. Phys. Chem. Chem. Phys. 5, 1329-1336. doi: 10.1039/b212047j

Díaz, J. A., Skrzynska, E., Girardon, J.-S., Capron, M., Dumeignil, F., and Fongarland, P. (2017). Glycerol oxidation in the liquid phase over a goldsupported catalyst: kinetic analysis and modelling. ChemEngineering 1, 1-14. doi: 10.3390/chemengineering 1010007

El Doukkali, M., Iriondo, A., Cambra, J. F., Gandarias, I., Jalowiecki-Duhamel, L., Dumeignil, F., et al. (2014). Deactivation study of the Pt and/or Ni-based $\gamma$-Al2O3 catalysts used in the aqueous phase reforming of glycerol for $\mathrm{H} 2$ production. Appl. Catal. Gen. 472, 80-91. doi: 10.1016/j.apcata.2013.12.015

Ftouni, J., Villandier, N., Auneau, F., Besson, M., Djakovitch, L., and Pinel, C. (2015). From glycerol to lactic acid under inert conditions in the presence of platinum-based catalysts: the influence of support. Catal. Today 257, 267-273. doi: 10.1016/j.cattod.2014.09.034

Hu, W., Knight, D., Lowry, B., and Varma, A. (2010). Selective oxidation of glycerol to dihydroxyacetone over $\mathrm{Pt}-\mathrm{Bi} / \mathrm{C}$ catalyst: optimization of catalyst and reaction conditions. Ind. Eng. Chem. Res. 49, 10876-10882. doi: 10.1021/ie1005096

Katryniok, B., Kimura, H., Skrzynska, E., Girardon, J.-S., Fongarland, P., Capron, M., et al. (2011). Selective catalytic oxidation of glycerol: perspectives for high value chemicals. Green Chem. 13, 1960-1979. doi: 10.1039/ C1GC15320J

\section{DATA AVAILABILITY}

All datasets generated for this study are included in the manuscript and/or the supplementary files.

\section{AUTHOR CONTRIBUTIONS}

AE: student who perform majority of the experiment; PF: contribution on the mechanism part; FD: contribution on the characterization part (XPS,...); MC: contribution on the reactivity part. All authors have contributed to the manuscript writing process.

\section{ACKNOWLEDGMENTS}

The Fonds Européen de Développement Régional (FEDER), CNRS, Région Nord Pas-de-Calais and Ministère de l'Education Nationale de l'Enseignement Supérieur et de la Recherche are acknowledged for fundings of XPS/LEIS/ToF-SIMS spectrometers within the Pôle Régional d'Analyses de Surface. This work was performed in partnership with the SAS PIVERT, within the frame of the French Institute for the Energy Transition (Institut pour la Transition Energétique (ITE) P.I.V.E.R.T. (www.institut-pivert.com) selected as an Investment for the Future (Investissements d'Avenir).
Katryniok, B., Paul, S., Bellière-Baca, V., Rey, P., and Dumeignil, F. (2010). Glycerol dehydration to acrolein in the context of new uses of glycerol. Green Chem. 12, 2079-2098. doi: 10.1039/c0gc00307g

Katryniok, B., Paul, S., Capron, M., and Dumeignil, F. (2009). Towards the sustainable production of acrolein by glycerol dehydration. ChemSusChem 2, 719-730. doi: 10.1002/cssc.200900134

Lauriol-Garbey, P., Millet, J. M. M., Loridant, S., Bellière-Baca, V., and Rey, P. (2011). New efficient and long-life catalyst for gas-phase glycerol dehydration to acrolein. J. Catal. 281, 362-370. doi: 10.1016/j.jcat.2011.05.014

Li, Y., and Zaera, F. (2015). Sensitivity of the glycerol oxidation reaction to the size and shape of the platinum nanoparticles in $\mathrm{Pt} / \mathrm{SiO} 2$ catalysts. J. Catal. 326, 116-126. doi: 10.1016/j.jcat.2015.04.009

Liebig, C., Paul, S., Katryniok, B., Guillon, C., Couturier, J.-L., Dubois, J.-L., et al. (2013). Glycerol conversion to acrylonitrile by consecutive dehydration over WO3/TiO2 and ammoxidation over Sb-(Fe,V)-O. Appl. Catal. B Environ. 132-133, 170-182. doi: 10.1016/j.apcatb.2012.11.035

Mimura, N., Hiyoshi, N., Daté, M., Fujitani, T., and Dumeignil, F. (2014). Microscope analysis of $\mathrm{Au}-\mathrm{Pd} / \mathrm{TiO} 2$ glycerol oxidation catalysts prepared by deposition-precipitation method. Catal. Lett. 144, 2167-2175. doi: 10.1007/s10562-014-1382-6

Purushothaman, R. K. P., van Haveren, J., Mayoral, A., Melián-Cabrera, I., and Heeres, H. J. (2014). Exploratory catalyst screening studies on the base free conversion of glycerol to lactic acid and glyceric acid in water using bimetallic Au-Pt nanoparticles on acidic zeolites. Top. Catal. 57, 1445-1453. doi: 10.1007/s11244-014-0316-2

Skrzynska, E., El Roz, A., Paul, S., Capron, M., and Dumeignil, F. (2019). Glycerol partial oxidation over $\mathrm{Pt} / \mathrm{Al}_{2} \mathrm{O}_{3}$ catalysts under basic and base-free conditions - effect of the particles size. J. Amer. Oil Chem. Soc. 96, 63-74. doi: 10.1002/aocs.12159

Skrzynska, E., Ftouni, J., Mamede, A.-S., Addad, A., Trentesaux, M., Girardon, J.-S., et al. (2014). Glycerol oxidation over gold supported catalysts - "Two 
faces" of sulphur based anchoring agent. J. Mol. Catal. Chem. 382, 71-78. doi: 10.1016/j.molcata.2013.11.007

Skrzynska, E., Zaid, S., Addad, A., Girardon, J.-S., Capron, M., and Dumeignil, F. (2016). Performance of $\mathrm{Ag} / \mathrm{Al}{ }_{2} \mathrm{O}_{3}$ catalysts in the liquid phase oxidation of glycerol - effect of preparation method and reaction conditions. Catal. Sci. Technol. 6, 3182-3196. doi: 10.1039/C5 CY01581B

Skrzynska, E., Zaid, S., Girardon, J.-S., Capron, M., and Dumeignil, F. (2015). Catalytic behaviour of four different supported noble metals in the crude glycerol oxidation. Appl. Catal. Gen. 499, 89-100. doi: 10.1016/j.apcata.2015.04.008

Wang, Y., Van de Vyver, S., Sharma, K. K., and Román-Leshkov, Y. (2014). Insights into the stability of gold nanoparticles supported on metal oxides for the base-free oxidation of glucose to gluconic acid. Green Chem. 16, 719-726. doi: 10.1039/C3GC41362D

Zaid, S., Skrzynska, E., Addad, A., Nandi, S., Jalowiecki-Duhamel, L., Girardon, J.-S., et al. (2017). Development of silver based catalysts promoted by noble metal $\mathrm{M}(\mathrm{M}=\mathrm{Au}, \mathrm{Pd}$ or $\mathrm{Pt})$ for glycerol oxidation in liquid phase. Top. Catal. 60, 1072-1081. doi: 10.1007/s11244017-0800-6

Zhang, M., Liang, D., Nie, R., Lu, X., Chen, P., and Hou, Z. (2012). Oxidation of biodiesel glycerol over Pt supported on different sized carbon supports in base-free solution. Chin. J. Catal. 33, 1340-1346. doi: 10.1016/S1872-2067(11)60411-7

Conflict of Interest Statement: The authors declare that the research was conducted in the absence of any commercial or financial relationships that could be construed as a potential conflict of interest.

Copyright (C) 2019 El Roz, Fongarland, Dumeignil and Capron. This is an open-access article distributed under the terms of the Creative Commons Attribution License (CC $B Y)$. The use, distribution or reproduction in other forums is permitted, provided the original author(s) and the copyright owner(s) are credited and that the original publication in this journal is cited, in accordance with accepted academic practice. No use, distribution or reproduction is permitted which does not comply with these terms. 